\title{
Ultrasonic Velocities of Molten Alkali Silicates
}

\author{
Miyuki HAYASHI, Yousuke MATSUZONO and Kazuhiro NAGATA \\ Department of Chemistry and Materials Science, Tokyo Institute of Technology, 2-12-1 Ookayama, Meguro-ku, Tokyo, 152- \\ 8552 Japan.
}

(Received on September 10, 2010; accepted on February 7, 2011)

\begin{abstract}
Temperature and compositional dependencies of ultrasonic velocities on molten alkali silicates have been reviewed. Although compositional correlation equations for the ultrasonic velocities on molten silicates have been previously proposed, the compositional dependency has not been interpreted yet from the viewpoint of the silicate structure. The authors focused on the ultrasonic velocities of molten alkali silicates, closely examined the reported data and have found that there is an identical linear relationship between the adiabatic compressibilities, which are strongly relevant to the ultrasonic velocities, and the molar volumes. This indicates that the molar volume is one of the most significant factors affecting the ultrasonic velocities.
\end{abstract}

KEY WORDS: ultrasonic velocity; adiabatic compressibility; molten alkali silicate; molar volume; density.

\section{Introduction}

Ultrasonics are defined as acoustic waves with frequencies above $20 \mathrm{kHz}$ up to around $1 \mathrm{GHz}$, while audio frequency is from $20 \mathrm{~Hz}$ to $20 \mathrm{kHz}$ although, with time, the upper limit has been reduced significantly. Ultrasonic waves have potential application in refining processes. For example, the size and distribution of nonmetallic inclusions in molten steel and the thickness of refractory walls of blast furnace can be estimated by using an ultrasonic inspection meter. Velocity and absorption coefficient of ultrasonic waves have also scientific interest because they are relevant to the thermodynamic and thermophysical properties such as adiabatic compressibility and volume viscosity. Since ultrasonic waves propagate in materials via phonons, the ultrasonic velocity is regarded as the velocity of phonons. According to Debye's equation, ${ }^{1)}$ the thermal conductivity of insulators is expressed by $\lambda=C v l / 3$ where $C$ is the heat capacity per unit volume, $v$ is the phonon velocity, i.e., the ultrasonic velocity, and $l$ is the phonon mean free path. As a result, the ultrasonic velocity allows the phonon mean free path to be evaluated. $^{2)}$

The ultrasonic velocity is generally independent of the frequency of waves used for the measurement. If it is assumed that the propagation of ultrasonic waves proceeds adiabatically and that local fluctuation of liquid density due to the propagation of ultrasonic waves is negligibly small, adiabatic compressibility $\beta_{\mathrm{s}}$ can be calculated from the determined velocity of ultrasonic waves $v$ with the equation,

$$
\beta_{s}=\frac{1}{\rho v^{2}}
$$

where $\rho$ is the density of the sample. The ultrasonic velocity generally decreases with increasing temperature as long as the coordination structure does not change. This is because thermal motion of the ions leads to an increase in the nearest- neighbor separation, resulting in an increase in compressibility. ${ }^{3)}$ It has been reported that ultrasonic velocity decreases with temperature for molten slags ${ }^{4-11)}$ and salts, ${ }^{12-15)}$ and many liquid metals. ${ }^{3,16,17)}$ Ultrasonic velocities of liquid metals have been reviewed by Iida and Guthrie. ${ }^{17)}$ In this paper, previous data of ultrasonic velocities on molten silicates will be reviewed at first. Then, the compositional dependency of ultrasonic velocities of molten alkali silicates will be discussed from the structural viewpoint.

\section{Experimental Methods}

Prior to introducing the previous data of ultrasonic velocities on molten silicates, the measurement methods of ultrasonic velocities will be briefly outlined. In most cases, high temperature ultrasonic measurements are carried out using a pulse technique. Ultrasonic pulse is generated and detected by a piezo-electric transducer of quartz or $\mathrm{BaTiO}_{3}$ crystals at room temperature and transmitted to the high temperature section of the furnace through a buffer rod made of fused silica or polycrystalline or single crystalline alumina. The ultrasonic pulse techniques can be divided into four classes (i) pulse echo technique, ${ }^{4,10)}$ (ii) pulse transmission technique, ${ }^{5,13,14,18)}$ (iii) pulse transmission/echo technique, ${ }^{19)}$ and (iv) interferometric method. ${ }^{6-9)}$ Pulse transmission/echo technique is suited to ultrasonic measurements at high pressure. Interferometric method is a derived form of the pulse echo or transmission technique. Some examples of this method have been explained elsewhere. ${ }^{8,18,20)}$ The principles of pulse echo and transmission techniques are presented together with some basic theories in the following subsections.

\subsection{Pulse Echo Technique}

A schematic diagram of the apparatus is shown in Fig. 1(i). Acoustic pulses generated by the transducer transmit 


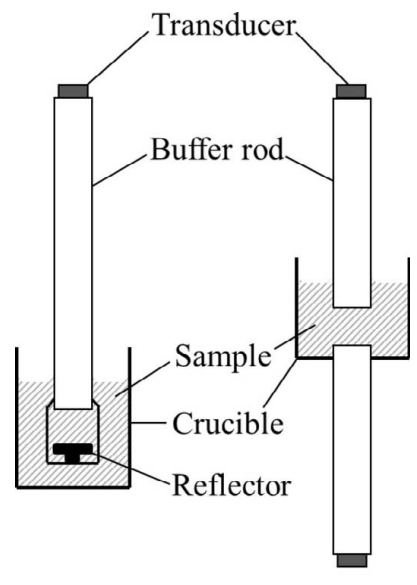

(i)

(ii)

Fig. 1. Cell assemblies of (i) pulse echo technique and (ii) pulse transmission technique.

through a buffer rod and are reflected at the interface between the rod and the sample. The reflected pulses come back through the rod to the transducer where acoustic pulses are converted to electrical pulses. A certain transmission of the pulses takes place from the rod to the sample. The pulses transmitted through the interface are reflected back by the reflector, travel through the rod to the transducer and generate delayed electrical pulses in the transducer. These are received, amplified and displayed on the oscilloscope with the first reflected pulses. When the distance between the end of the rod and the reflector is known, the time delay between the pulse reflected at the interface (between the rod and the sample) and the pulse reflected by the reflector gives the desired velocity of ultrasonic waves.

The aforementioned technique is based on a characteristic of ultrasonics that ultrasonic waves reflect at the interface between two different media. When two media 1 and 2 stay in intimate contact at a perfect interface and the normal incident wave comes from medium 1, the reflection coefficient at the interface between two media is given by ${ }^{21)}$

$$
R=\frac{Z_{2}-Z_{1}}{Z_{2}+Z_{1}}
$$

where $Z_{1}$ and $Z_{2}$ are specific acoustic impedance of media 1 and 2 . Acoustic impedance is obtained by multiplying density $\rho$ by velocity of ultrasonic waves $v$.

$$
Z=\rho v
$$

Of great importance are the acoustic intensity reflection and transmission coefficient, $R_{\mathrm{P}}$ and $T_{\mathrm{P}}$.

$$
\begin{gathered}
R_{\mathrm{P}}=|R|^{2} . \\
T_{\mathrm{P}}=1-|R|^{2} .
\end{gathered}
$$

Now, it is assumed that the sample in Fig. 1(i) is molten $50 \mathrm{Na}_{2} \mathrm{O}(\mathrm{mol} \%)-50 \mathrm{SiO}_{2}$ slag. Let's consider the optimal materials for the reflector. The values of $\rho$ and $v$ are $2.24 \times 10^{3} \mathrm{~kg} \cdot \mathrm{m}^{-322)}$ and $2.8 \mathrm{~km} \cdot \mathrm{s}^{-1}$, 4 respectively, for $50 \mathrm{Na}_{2} \mathrm{O}$ (mol\%) $-50 \mathrm{SiO}_{2}$ slag at $1400 \mathrm{~K}$, giving a longitudinal acoustic impedance of 6.3 MRayls $\left(10^{6} \mathrm{~N} \cdot \mathrm{s} \cdot \mathrm{m}^{-3}\right)$ where the Rayl (after Lord Rayleigh) is the MKS unit of acoustic impedance. Poor reactive materials for molten silicates may be
$\mathrm{Al}_{2} \mathrm{O}_{3}$ and platinum, for instance. The values of $\rho$ and $v$ of sintered almina are $3.9 \times 10^{3} \mathrm{~kg} \cdot \mathrm{m}^{-3}$ and $10 \mathrm{~km} \cdot \mathrm{s}^{-1}$ 23) and $\rho$ and $v$ of platinum are $21.62 \times 10^{3} \mathrm{~kg} \cdot \mathrm{m}^{-3}$ and $3.26 \mathrm{~km} \cdot \mathrm{s}^{-1},{ }^{24)}$ giving a longitudinal acoustic impedance of 40.1 and 70.5 MRayls, respectively. Consequently, when sintered alumina and platinum are used as the reflector materials, the acoustic intensity reflection coefficients $R_{\mathrm{P}}$ can be calculated as 0.73 and 0.84 , respectively. This indicates that platinum is somewhat better than sintered alumina as the reflector material for measuring the velocity of ultrasonic waves of molten silicates.

The advantage of pulse echo technique is that the cell design is simpler than that of the pulse transmission technique. However, the technique has a drawback in that the main pulse is more likely to be affected by the trailing pulse generated by incoherent reflections from the surface of the rod.

\subsection{Pulse Transmission Technique}

This technique is employed for the liquid sample. In this technique, pairs of buffer rods and transducers are used as shown in Fig. 1(ii). Acoustic pulses generated from the upper (or lower) transducer travel through the attached rod, the liquid and the other rod in turn, and are received by the lower (or upper) transducer. The upper rod can be vertically shifted by a distance $\Delta x$, which is measured very accurately by, for instance, a micro screw gauge or a cathetometer. The time required for a pulse to travel from one transducer to another is precisely measured by an oscilloscope. The velocity of ultrasonic waves $(v)$ can be calculated by dividing the change in the distance between two ends of the rods $(\Delta x)$ by the change in the time of the travel of the ultrasonic pulses $(\Delta t)$.

$$
v=\frac{\Delta x}{\Delta t}
$$

The velocity of ultrasonic waves can also be determined by measuring the ultrasonic wavelength $(\lambda)$ and frequency $(f)$, i.e., $v=\lambda / f$. $^{18,25)}$

\section{Factors Affecting the Ultrasonic Velocities of Molten Silicates}

\subsection{Temperature Dependency}

Table 1 summarizes the previous studies with respect to the ultrasonic velocities of molten silicates. For all the data except for only one system, velocity decreases with an increase in temperature; for the $\mathrm{PbO}-\mathrm{SiO}_{2}$ system, temperature dependencies are negligibly small at least over the measurement temperature range of $200 \mathrm{~K}^{4}{ }^{4}$ Figures 2-4 show the temperature dependencies of the ultrasonic velocities on $33(\mathrm{~mol} \%) \mathrm{M}_{2} \mathrm{O}-67 \mathrm{SiO}_{2}$ and $50(\mathrm{~mol} \%) \mathrm{M}_{2} \mathrm{O}-50 \mathrm{SiO}_{2}$ $(\mathrm{M}=\mathrm{Li}, \mathrm{Na}$ and $\mathrm{K})$ in the liquid states. Because of the reasons described in Section 4, the data of $\mathrm{Li}_{2} \mathrm{O}-\mathrm{SiO}_{2}$ system reported by Bloom and Bockris ${ }^{7}$ and the data of $\mathrm{Na}_{2} \mathrm{O}-\mathrm{SiO}_{2}$ and $\mathrm{K}_{2} \mathrm{O}-\mathrm{SiO}_{2}$ systems by Shiraishi et al. ${ }^{5)}$ were not adopted for Figs. 2-4. It is seen that there are discrepancies among reported data for the $\mathrm{K}_{2} \mathrm{O}-\mathrm{SiO}_{2}$ system.

\subsection{Composition Dependency}

Rivers and Carmichael ${ }^{8)}$ have reported two compositional 
Table 1. Previous ultrasonic velocity studies on molten silicates.

\begin{tabular}{|c|c|c|c|}
\hline $\begin{array}{l}\text { Reference } \\
\text { number }\end{array}$ & Authors & System & $\begin{array}{c}\text { Number of } \\
\text { compositions }\end{array}$ \\
\hline \multirow[t]{3}{*}{ 4) } & Nagata et al. & $\mathrm{Na}_{2} \mathrm{O}-\mathrm{SiO}_{2}$ & 3 \\
\hline & & $\mathrm{K}_{2} \mathrm{O}-\mathrm{SiO}_{2}$ & 2 \\
\hline & & $\mathrm{PbO}-\mathrm{SiO}_{2}$ & 2 \\
\hline \multirow[t]{4}{*}{ 5) } & Shiraishi et al. & $\mathrm{Li}_{2} \mathrm{O}-\mathrm{SiO}_{2}$ & 4 \\
\hline & & $\mathrm{Na}_{2} \mathrm{O}-\mathrm{SiO}_{2}$ & 3 \\
\hline & & $\mathrm{K}_{2} \mathrm{O}-\mathrm{SiO}_{2}$ & 4 \\
\hline & & $\mathrm{Li}_{2} \mathrm{O}-\mathrm{Na}_{2} \mathrm{O}-\mathrm{SiO}_{2}$ & 3 \\
\hline \multirow[t]{3}{*}{ 6) } & Baidov and Kunin & $\mathrm{Li}_{2} \mathrm{O}-\mathrm{SiO}_{2}$ & 13 \\
\hline & & $\mathrm{K}_{2} \mathrm{O}-\mathrm{SiO}_{2}$ & 7 \\
\hline & & $\mathrm{CaO}-\mathrm{SiO}_{2}$ & 11 \\
\hline 7) & Bloom and Bockris & $\mathrm{Li}_{2} \mathrm{O}-\mathrm{SiO}_{2}$ & 6 \\
\hline \multirow[t]{6}{*}{ 8) } & Rivers and Carmichael & $\mathrm{Li}_{2} \mathrm{O}-\mathrm{SiO}_{2}$ & 2 \\
\hline & & $\mathrm{Na}_{2} \mathrm{O}-\mathrm{SiO}_{2}$ & 2 \\
\hline & & $\mathrm{K}_{2} \mathrm{O}-\mathrm{SiO}_{2}$ & 2 \\
\hline & & $\mathrm{Rb}_{2} \mathrm{O}-\mathrm{SiO}_{2}$ & 1 \\
\hline & & $\mathrm{Cs}_{2} \mathrm{O}-\mathrm{SiO}_{2}$ & 1 \\
\hline & & Binary and multi component systems & \\
\hline \multirow[t]{2}{*}{ 9) } & Bockris and Kojonen & $\mathrm{Na}_{2} \mathrm{O}-\mathrm{SiO}_{2}$ & 9 \\
\hline & & $\mathrm{K}_{2} \mathrm{O}-\mathrm{SiO}_{2}$ & 6 \\
\hline \multirow[t]{2}{*}{$10,11)$} & Matsuzono et al. & $\mathrm{Li}_{2} \mathrm{O}-\mathrm{SiO}_{2}$ & 1 \\
\hline & & $\mathrm{Na}_{2} \mathrm{O}-\mathrm{SiO}_{2}$ & 3 \\
\hline
\end{tabular}

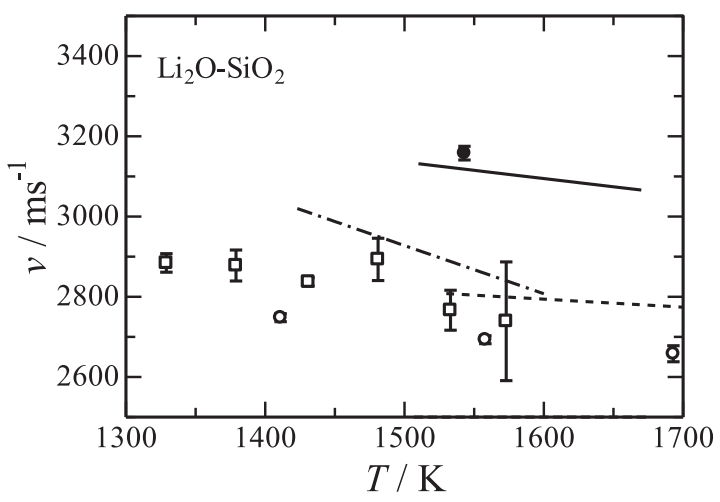

$$
\begin{aligned}
& 33(\mathrm{~mol} \%) \mathrm{Li}_{2} \mathrm{O}-67 \mathrm{SiO}_{2} \\
&-\cdot-\cdot-\cdot \text { Shiraishi et al. } \\
& \mathbf{-}-\boldsymbol{-} \text { Baidov and Kunin } \\
& \text { ○ } \text { Rivers and Carmichael } \\
& \text { 口 } \text { Matsuzono et al. }
\end{aligned}
$$

$50\left(\mathrm{~mol}_{\%}\right) \mathrm{Li}_{2} \mathrm{O}-50 \mathrm{SiO}_{2}$

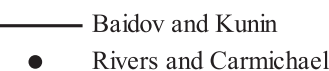

Fig. 2. Temperature dependency of the ultrasonic velocity on $33(\mathrm{~mol} \%) \mathrm{Li}_{2} \mathrm{O}-67 \mathrm{SiO}_{2}$ and $50(\mathrm{~mol} \%) \mathrm{Li}_{2} \mathrm{O}-50 \mathrm{SiO}_{2}$ in the liquid states.

correlation equations for the ultrasonic velocities of molten silicates. One of two is the equation proposed by Ernest et $a l .{ }^{26)}$ Ernest et al. have made the argument that if a solution mixes without volume change, one can imagine separating the liquid into layers whose thickness is proportional to the volume fraction of each component, $x_{i, v}$. The total time for an acoustic wave to transverse the system is equal to the sum of the times required to pass through each layer, $x_{i, v} / v_{i}$, where $v_{i}$ is the sound speed of layer $i$. Thus

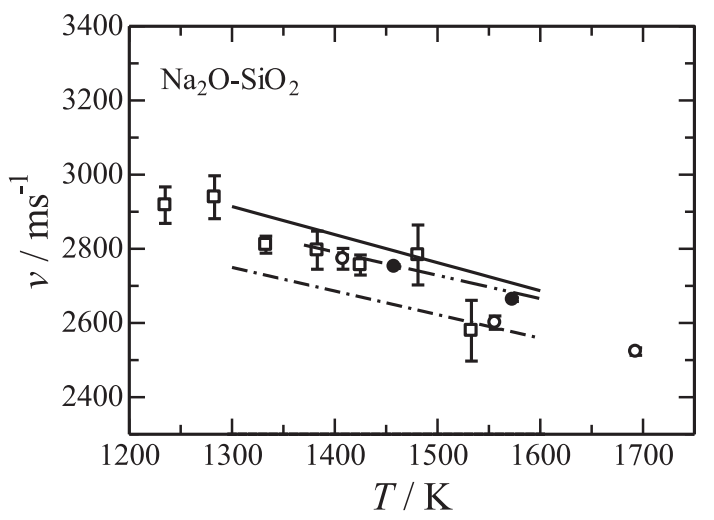

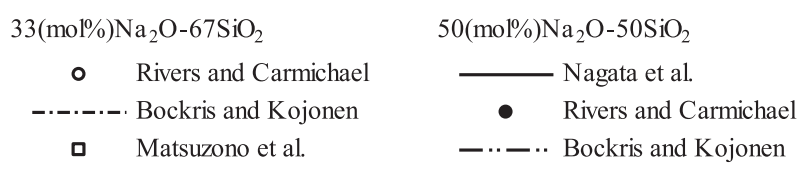

Fig. 3. Temperature dependency of the ultrasonic velocity on $33(\mathrm{~mol} \%) \mathrm{Na}_{2} \mathrm{O}-67 \mathrm{SiO}_{2}$ and $50(\mathrm{~mol} \%) \mathrm{Na}_{2} \mathrm{O}-50 \mathrm{SiO}_{2}$ in the liquid states.

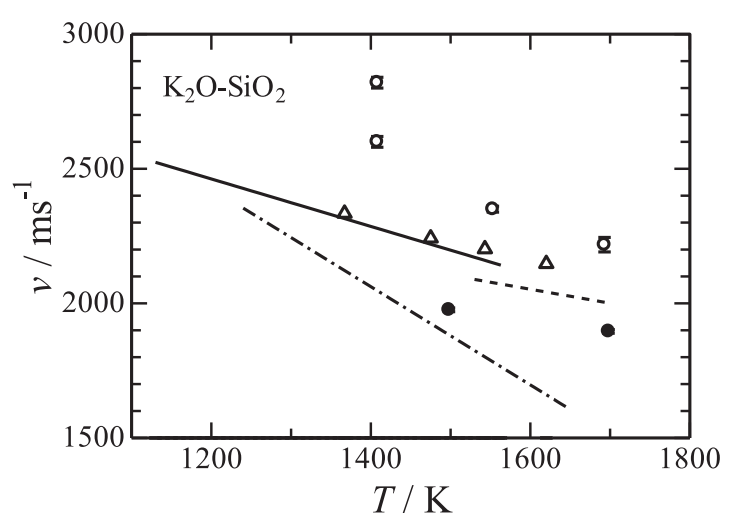

$$
\begin{aligned}
& 33(\mathrm{~mol} \%) \mathrm{K}_{2} \mathrm{O}-67 \mathrm{SiO}_{2} \quad 50\left(\mathrm{~mol}_{2}\right) \mathrm{K}_{2} \mathrm{O}-50 \mathrm{SiO}_{2} \\
& \text { - - - - Baidov and Kunin N N Nagata et al. } \\
& \text { - Rivers and Carmichael - Rivers and Carmichael } \\
& \Delta \quad \text { Bockris and Kojonen } \quad \text { - } \cdot \text { - } \cdot \text { - Bockris and Kojonen }
\end{aligned}
$$

Fig. 4. Temperature dependency of the ultrasonic velocity on $33(\mathrm{~mol} \%) \mathrm{K}_{2} \mathrm{O}-67 \mathrm{SiO}_{2}$ and $50(\mathrm{~mol} \%) \mathrm{K}_{2} \mathrm{O}-50 \mathrm{SiO}_{2}$ in the liquid states.

$$
\frac{1}{v}=\sum \frac{x_{i, v}}{v_{i}}
$$

Here, $v_{i}$ will be referred to as the sound speed coefficient of component $i$, which is the definition adopted by Ernest et $a l$. for the sound speed in an ideal solution. Rivers and Carmichael $^{8)}$ have derived the values of $v_{i}$ for the 13 oxide components from a multiple linear regression fit to Eq. (7) for the 65 liquid compositions at $1673 \mathrm{~K}$. For instance, the values of $v_{i}$ for $\mathrm{SiO}_{2}, \mathrm{Li}_{2} \mathrm{O}, \mathrm{Na}_{2} \mathrm{O}$ and $\mathrm{K}_{2} \mathrm{O}$ are 2 524, 4265 , 2639 and $1660 \mathrm{~m} \cdot \mathrm{s}^{-1}$, respectively. It may be surprising that the value of $v_{i}$ for $\mathrm{SiO}_{2}$ is relatively small and between the values for $\mathrm{Li}_{2} \mathrm{O}$ and $\mathrm{K}_{2} \mathrm{O}$. This means that ultrasonic velocity does not seem to be related to the ionicity or covelency of bonding. In fact, this small ultrasonic velocity, i.e., large compressibility for $\mathrm{SiO}_{2}$ is in accord with the results reported by Laberge et al. ${ }^{27)}$ and Bucaro and Dardy. ${ }^{28)}$ However, the compositional dependency of ultrasonic velocities of molten silicates has not been interpreted yet from the view- 
point of the structure. One of the reasons why the compositional dependency has not been elucidated yet is that there are large discrepancies among reported ultrasonic velocities of molten silicates.

The authors will focus on the ultrasonic velocities of molten alkali silicates, closely examine the reported data and investigate the relationship between the ultrasonic velocities and the structures.

\section{Composition Dependency of Ultrasonic Velocities and Adiabatic Compressibilities on Molten Alkali Silicates}

Figures 5-7 show the velocities of the $\mathrm{M}_{2} \mathrm{O}-\mathrm{SiO}_{2}$ systems $(\mathrm{M}=\mathrm{Li}, \mathrm{Na}$ and $\mathrm{K})$ at $1573 \mathrm{~K}$ as a function of the $\mathrm{M}_{2} \mathrm{O}$ content. The velocity of the $\mathrm{Li}_{2} \mathrm{O}-\mathrm{SiO}_{2}$ system increases from ca. $2700 \mathrm{~m} \cdot \mathrm{s}^{-1}$ to ca. $3200 \mathrm{~m} \cdot \mathrm{s}^{-1}$ with increasing the $\mathrm{Li}_{2} \mathrm{O}$ content from $30 \mathrm{~mol} \%$ to $60 \mathrm{~mol} \%$ except for the data reported by Bloom and Bockris. ${ }^{7)}$ With respect to the discrepancy between the data by Bloom and Bockris and others, Baidov and Kunin ${ }^{6}$ and Rivers and Carmichael ${ }^{8)}$ have pointed out that the alumina buffer rods that Bloom and Bockris used may have been seriously corroded in the melts during the experiment. Corrosion of alumina buffer rods would increase the true wave path length in the melts, leading to an underestimate of the sound speed. The velocity of the $\mathrm{Na}_{2} \mathrm{O}-\mathrm{SiO}_{2}$ system slightly increases from ca. $2500 \mathrm{~m} \cdot \mathrm{s}^{-1}$ to ca. $2700 \mathrm{~m} \cdot \mathrm{s}^{-1}$ with increasing the $\mathrm{Na}_{2} \mathrm{O}$ content from 15 $\mathrm{mol} \%$ to $60 \mathrm{~mol} \%$ except for the data reported by Shiraishi et $a l .{ }^{5)}$ The reason for the deviation in the results of Shiraishi et al. is not clear. On the other hand, the velocity of the $\mathrm{K}_{2} \mathrm{O}-\mathrm{SiO}_{2}$ system decreases from ca. $2400 \mathrm{~m} \cdot \mathrm{s}^{-1}$ to ca. 1800 $\mathrm{m} \cdot \mathrm{s}^{-1}$ with an increase in the $\mathrm{K}_{2} \mathrm{O}$ content from $20 \mathrm{~mol} \%$ to $50 \mathrm{~mol} \%$ except for the value obtained by Shiraishi et al., ${ }^{5)}$ which is much higher than other data. They have used an ultrasonic frequency as large as $10 \mathrm{MHz}$ while other researchers have used frequencies less than $4 \mathrm{MHz}$. As aforementioned, the ultrasonic velocity is generally independent of the frequency of waves, i.e., dispersionless. Dispersion means that the velocity varies with frequency. In fact, dispersion happens at very high frequencies (for exam-

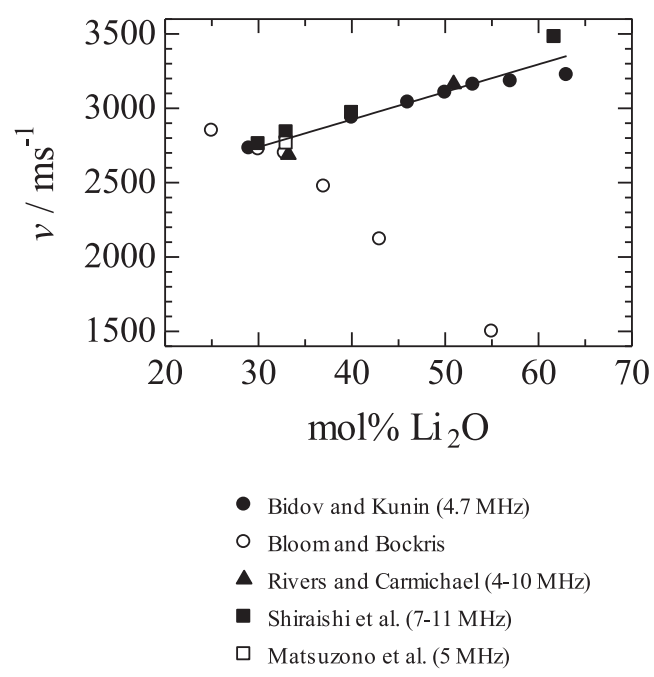

Fig. 5. Velocities of the $\mathrm{Li}_{2} \mathrm{O}-\mathrm{SiO}_{2}$ systems at $1573 \mathrm{~K}$ as a function of the $\mathrm{Li}_{2} \mathrm{O}$ content (mol\%). ple, with thermal phonons near the Brillouin zone boundaries) or for high viscous materials, in which part of the atomic movements cannot follow high frequencies of ultrasonics. In such an unrelaxed region, the velocity increases with an increase in the frequency. In fact, Bidov and Kunin $\left.{ }^{6}\right)$ have measured the velocities at the frequencies of 1 and 4.7 $\mathrm{MHz}$, and have observed the dispersion in the melts of $\mathrm{K}_{2} \mathrm{O}-$ $\mathrm{SiO}_{2}$ having viscosities of the order of magnitude $100 \mathrm{~Pa} \cdot \mathrm{s}$. Therefore, it is considered that $10 \mathrm{MHz}$ is the frequency far above the relaxation region of the melt, and Shiraishi et al. have measured an unrelaxed ultrasonic velocity.

In order to discuss the compositional dependency of ultrasonic velocities from the structural viewpoint, adiabatic compressibility obtained by Eq. (1) may have to be considered because compressibility is more directly relevant to the structure rather than velocity. In order to obtain the adiabatic compressibilities, the density values are required. Figure 8 shows the densities of the $\mathrm{M}_{2} \mathrm{O}-\mathrm{SiO}_{2}$ systems $(\mathrm{M}=\mathrm{Li}, \mathrm{Na}$ and $\mathrm{K}$ ) at $1573 \mathrm{~K}$ as a function of the $\mathrm{M}_{2} \mathrm{O}$ content. ${ }^{7,22,29-33)}$ Bloom and Bockris, ${ }^{7)}$ Shartsis et al. ${ }^{29}$ and Šašek and Lisý $^{30,31)}$ have used the direct Archimedes method in which

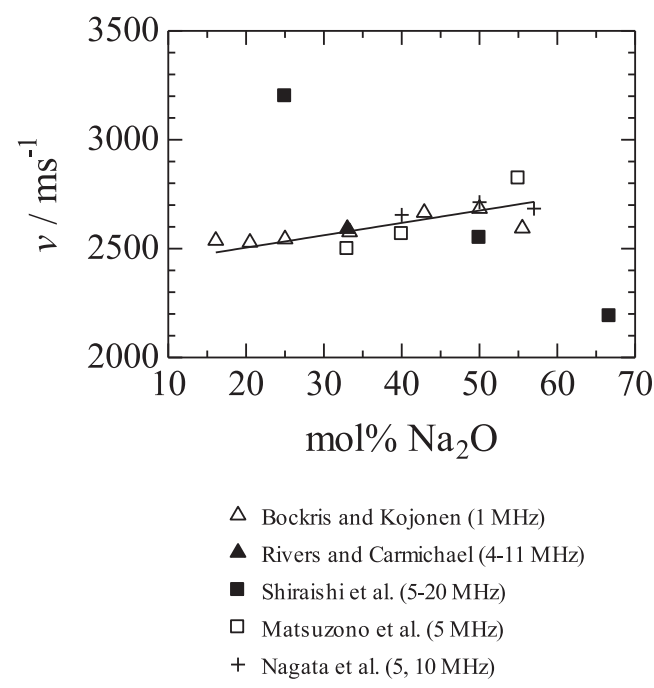

Fig. 6. Velocities of the $\mathrm{Na}_{2} \mathrm{O}-\mathrm{SiO}_{2}$ systems at $1573 \mathrm{~K}$ as a function of the $\mathrm{Na}_{2} \mathrm{O}$ content (mol\%).

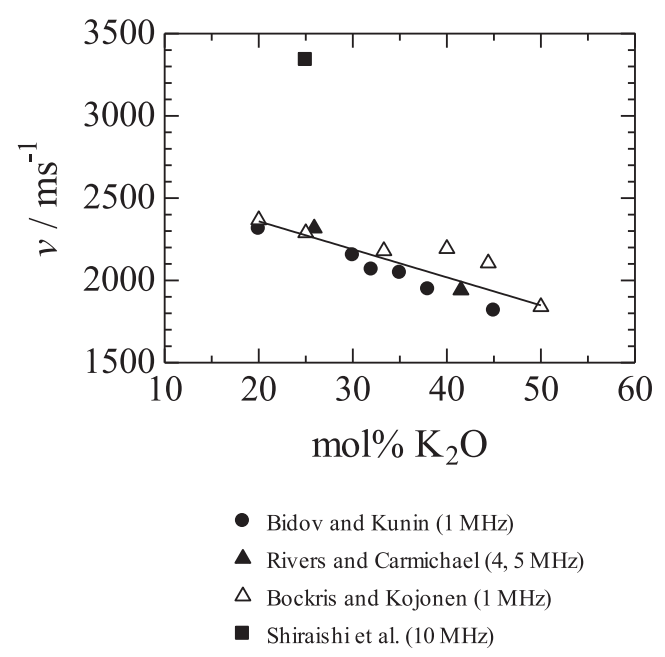

Fig. 7. Velocities of the $\mathrm{K}_{2} \mathrm{O}-\mathrm{SiO}_{2}$ systems at $1573 \mathrm{~K}$ as a function of the $\mathrm{K}_{2} \mathrm{O}$ content (mol\%). 

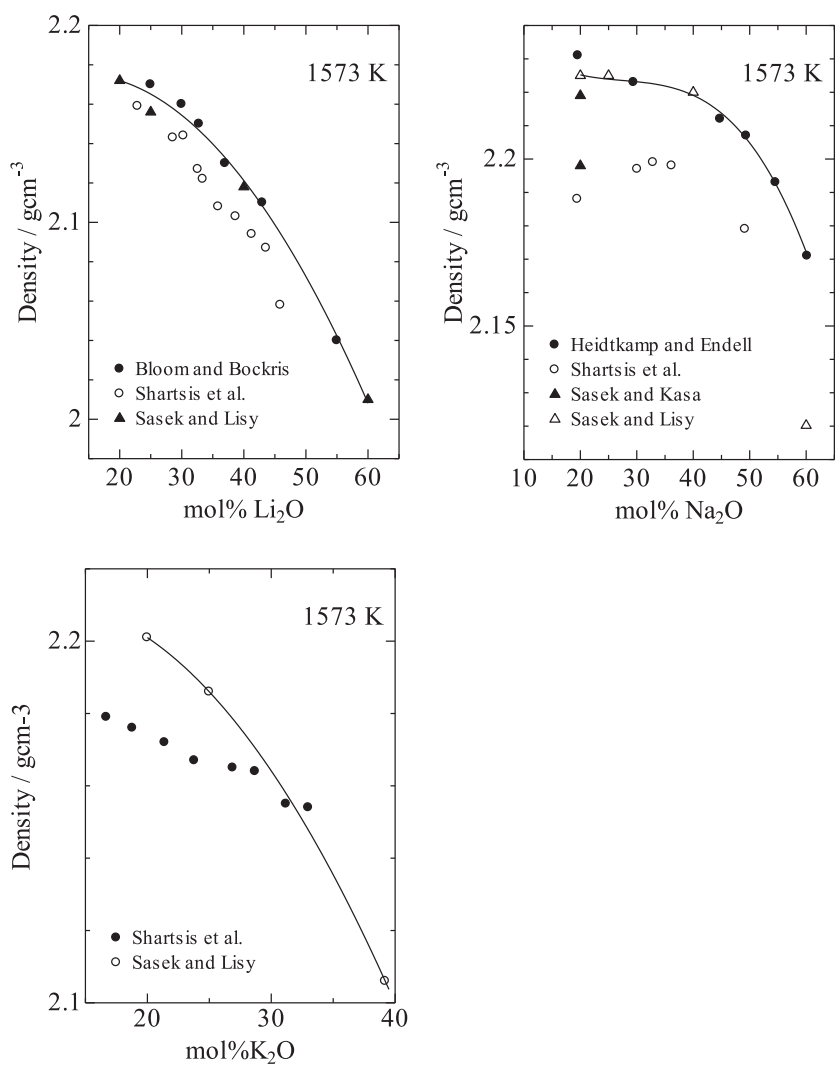

Fig. 8. Densities of the $\mathrm{M}_{2} \mathrm{O}-\mathrm{SiO}_{2}$ systems $(\mathrm{M}=\mathrm{Li}, \mathrm{Na}$ and $\mathrm{K})$ at $1573 \mathrm{~K}$ as a function of the $\mathrm{M}_{2} \mathrm{O}$ content (mol\%).

platinum or platinum-rhodium bob of known weight is suspended by a wire attached to the arm of a balance, and the bob is immersed in a molten glass specimen in platinum or platinum-rhodium crucible. Heidtkamp and Endell ${ }^{32)}$ have used the indirect Archimedes method for the $\mathrm{Na}_{2} \mathrm{O}-\mathrm{SiO}_{2}$ system with lower $\mathrm{Na}_{2} \mathrm{O}$ content (less than $30 \mathrm{~mol} \% \mathrm{Na}_{2} \mathrm{O}$ ), in which a molten glass specimen contained in a platinum crucible is weighted while immersed in $\mathrm{NaCl}$ melt. They have used the direct Archimedes method for higher $\mathrm{Na}_{2} \mathrm{O}$ content. Šašek and $\mathrm{Kasa}^{33)}$ have measured the density of $20(\mathrm{~mol} \%) \mathrm{Na}_{2} \mathrm{O}-\mathrm{SiO}_{2}$ by two different methods; the direct Archimedes method and the maximum bubble pressure method, to be 2.219 and 2.198, respectively. Inspection of Fig. 8 indicates that the data obtained by Shartsis et al. ${ }^{29)}$ are lower than the other data for all the three systems. In this study, the compositional dependencies of the densities, $\rho$ $\left(\mathrm{g} \cdot \mathrm{cm}^{-3}\right)$ have been derived by the least square fitting of the data obtained by Bloom and Bockris, ${ }^{7)}$ Šašek and Lisý, ${ }^{30,31)}$ Heidtkamp and Endell ${ }^{32)}$ and Šašek and $\mathrm{Kasa}^{33)}$ using the direct and indirect Archimedes methos as follows:

$$
\begin{aligned}
\mathrm{Li}_{2} \mathrm{O}-\mathrm{SiO}_{2}: \rho\left(\mathrm{g} \cdot \mathrm{cm}^{-3}\right)= & 2.160+2.136 \cdot 10^{-3} \cdot x \\
-7.789 \cdot 10^{-5} \cdot x^{2} & \left(20 \leq x \leq 60 \mathrm{~mol} \% \mathrm{Li}_{2} \mathrm{O}\right)
\end{aligned}
$$

$\mathrm{Na}_{2} \mathrm{O}-\mathrm{SiO}_{2}: \rho\left(\mathrm{g} \cdot \mathrm{cm}^{-3}\right)=2.250-2.617 \cdot 10^{-3} \cdot x+9.345 \cdot 10^{-5} \cdot x^{2}$ $-1.180 \cdot 10^{-6} \cdot x^{3} \quad\left(20 \leq x \leq 60 \mathrm{~mol} \% \mathrm{Na}_{2} \mathrm{O}\right)$...

$\mathrm{K}_{2} \mathrm{O}-\mathrm{SiO}_{2}: \rho\left(\mathrm{g} \cdot \mathrm{cm}^{-3}\right)=2.192+3.173 \cdot 10^{-3} \cdot x$

$$
-1.372 \cdot 10^{-4} \cdot x^{2} \quad\left(20 \leq x \leq 40 \mathrm{~mol}^{2} \mathrm{~K}_{2} \mathrm{O}\right) \text {. }
$$

The above equations are used to estimate the densities so as to calculate the adiabatic compressibilities, as shown in Figs. 9-11.

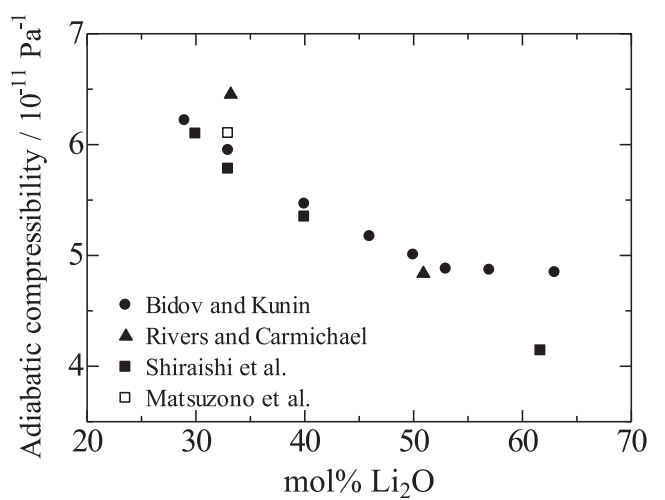

Fig. 9. Adiabatic compressibilities of the $\mathrm{Li}_{2} \mathrm{O}-\mathrm{SiO}_{2}$ systems at $1573 \mathrm{~K}$ as a function of the $\mathrm{Li}_{2} \mathrm{O}$ content (mol\%).

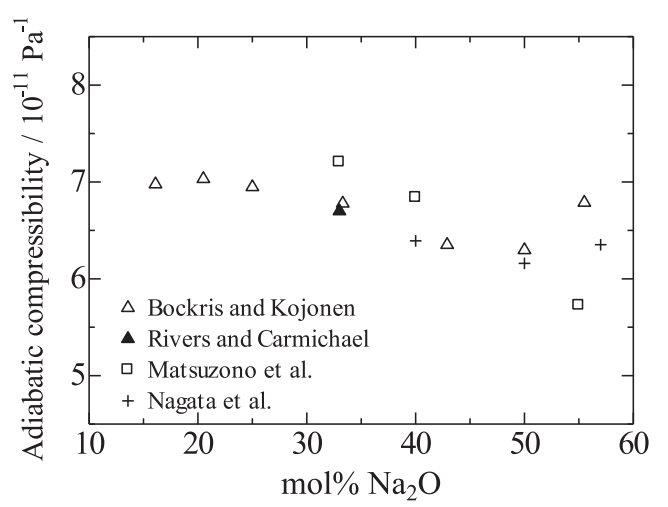

Fig. 10. Adiabatic compressibilities of the $\mathrm{Na}_{2} \mathrm{O}-\mathrm{SiO}_{2}$ systems at $1573 \mathrm{~K}$ as a function of the $\mathrm{Na}_{2} \mathrm{O}$ content ( $\mathrm{mol} \%$ ).

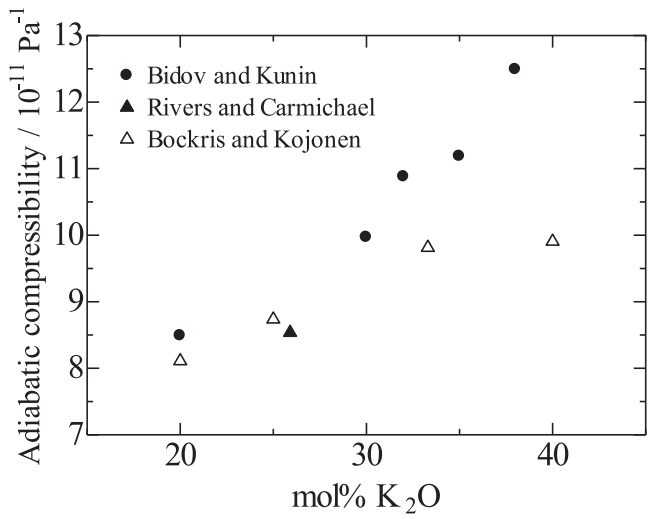

Fig. 11. Adiabatic compressibilities of the $\mathrm{K}_{2} \mathrm{O}-\mathrm{SiO}_{2}$ systems at $1573 \mathrm{~K}$ as a function of the $\mathrm{K}_{2} \mathrm{O}$ content (mol\%).

\section{Relation Between Adiabatic Compressibility and Molar Volume}

Rivers and Carmichael ${ }^{8)}$ have discussed the compositional dependence of adiabatic compressibility assuming an ideal solution: Stebbins et al. ${ }^{34)}$ state that applying a simple ideal mixing model

$$
V(T)=\sum_{i} x_{i} V_{i}
$$

to all existing high-quality volume measurements on silicate melts yields a standard error of the fit of less than $1 \%$. If the volume mixes ideally at pressures other than $1 \mathrm{~atm}$, then 


$$
V(P, T)=\sum_{i} x_{i} V_{i}(P, T)
$$

Differentiation with respect to pressure yields

$$
\left(\frac{\partial V}{\partial P}\right)_{T}=\sum_{i} x_{i}\left(\frac{\partial V_{i}}{\partial P}\right)_{T}
$$

Prigogine and Defay ${ }^{35)}$ define the compressibility coefficient of an ideal solution as

$$
\beta_{i}=-\frac{1}{V_{i}}\left(\frac{\partial V_{i}}{\partial P}\right)_{T}
$$

Combining Eqs. (13) and (14) yields

$$
-\frac{\partial V}{\partial P}=V \beta=\sum_{i} x_{i} V_{i} \beta_{i}
$$

Dividing by $V$

$$
\beta=\frac{\sum_{i} x_{i} V_{i}}{V} \beta_{i}
$$

$x_{i} V_{i} / V$ is just the volume fraction of component $i, x_{i, v}$. Thus for an ideal solution

$$
\beta=\sum_{i} x_{i, v} \beta_{i}
$$

and compressibility mixes linealy in volume fraction of the components. Rivers and Carmichael ${ }^{6)}$ have derived $\left(\partial V_{i} / \partial P\right)_{T}$ for the 13 oxide components by multiple linear regression of the 65 melt compositions, and have plotted the $-\left(\partial V_{i} / \partial P\right)_{T}$ values as a function of the molar volume of each oxide component, $V_{i}$. Rivers and Carmichael $^{8)}$ have reported that the $-\left(\partial V_{i} / \partial P\right)_{T}$ values monotonically increase with an increase in the $V_{i}$ values, and that the data are on an identical curve of $-\left(\partial V_{i} / \partial P\right)_{T}$ vs. molar volume irrespective of any oxide component.

However, the inspection of $-\left(\partial V_{i} / \partial P\right)_{T}$ vs. $V_{i}$ curve reported by Rivers and Carmichael ${ }^{8)}$ presents that the curve is not linear but convex downward. Combination of this fact with Eq. (14) indicates that $\beta_{i}$ may become larger as the molar volume is larger. This prediction is quite reasonable as the component with larger molar volume may have more free space between ions for compression. Therefore, the adiabatic compressibilities of the $\mathrm{M}_{2} \mathrm{O}-\mathrm{SiO}_{2}$ systems $(\mathrm{M}=\mathrm{Li}, \mathrm{Na}$ and $\mathrm{K}$ ) at $1573 \mathrm{~K}$ are plotted against the molar volumes as shown in Fig. 12. It can be found that there is an identical linear relation between the adiabatic compressibilities and

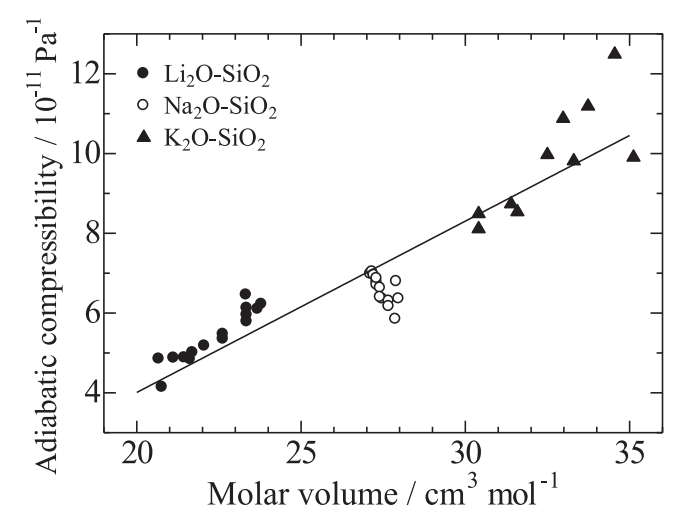

Fig. 12. Adiabatic compressibilities of the $\mathrm{M}_{2} \mathrm{O}-\mathrm{SiO}_{2}$ systems $(\mathrm{M}=$ $\mathrm{Li}, \mathrm{Na}$ and $\mathrm{K}$ ) at $1573 \mathrm{~K}$ as a function of the $\mathrm{M}_{2} \mathrm{O}$ content $(\mathrm{mol} \%)$. the molar volumes. This indicates that the molar volume is one of the most significant factors affecting the ultrasonic velocity value. The same systems at other temperatures as well as other systems including molten salts will be carefully considered in the future.

\section{Conclusions}

After the measurement methods of ultrasonic velocities were briefly outlined, previous data of ultrasonic velocities on molten silicates have been reviewed. It has been reported that ultrasonic velocity decreases with temperature for all the molten silicates except for the $\mathrm{PbO}-\mathrm{SiO}_{2}$ system. With respect to the compositional dependency, two compositional correlation equations for the ultrasonic velocities of molten silicates have been proposed. However, the compositional dependency of ultrasonic velocities of molten silicates has not been interpreted yet from the viewpoint of the structure.

The authors focused on the ultrasonic velocities of molten alkali silicates, closely examined the reported data and investigated the relationship between the ultrasonic velocities and the structures. The following results have been obtained.

(1) The velocities of the $\mathrm{Li}_{2} \mathrm{O}-\mathrm{SiO}_{2}, \mathrm{Na}_{2} \mathrm{O}-\mathrm{SiO}_{2}$ and $\mathrm{K}_{2} \mathrm{O}-\mathrm{SiO}_{2}$ systems increase from ca. $2700 \mathrm{~m} \cdot \mathrm{s}^{-1}$ to ca. 3200 $\mathrm{m} \cdot \mathrm{s}^{-1}$ with increasing the $\mathrm{Li}_{2} \mathrm{O}$ content from $30 \mathrm{~mol} \%$ to 60 $\mathrm{mol} \%$, slightly increase from ca. $2500 \mathrm{~m} \cdot \mathrm{s}^{-1}$ to ca. $2700 \mathrm{~m} \cdot \mathrm{s}^{-1}$ with increasing the $\mathrm{Na}_{2} \mathrm{O}$ content from $15 \mathrm{~mol} \%$ to $60 \mathrm{~mol} \%$ and decrease from ca. $2400 \mathrm{~m} \cdot \mathrm{s}^{-1}$ to ca. $1800 \mathrm{~m} \cdot \mathrm{s}^{-1}$ with an increase in the $\mathrm{K}_{2} \mathrm{O}$ content from $20 \mathrm{~mol} \%$ to $50 \mathrm{~mol} \%$, respectively. This means that ultrasonic velocity does not seem to be related to the ionicity or covelency of bonding.

(2) It has been found that there is an identical linear relation between the adiabatic compressibilities and the molar volumes. This indicates that the molar volume is one of the most significant factors affecting the ultrasonic velocity values.

\section{REFERENCES}

1) P. Debye: Vorträge über die Kinetische Theorie der Materie und der Elektrizität, Teubner, Berlin, (1914), 19.

2) K. Nagata and K. S. Goto: Proc. 2nd Int. Symp. on Metallurgical Slags and Fluxes, Metall. Soc. AIME, Warrendale, PA, (1984), 875.

3) W. P. Mason: Physical Acoustics, vol.IV, part B, Academic Press, (1968) 57.

4) K. Nagata, K. Ohira, H. Yamada and K. S. Goto: Metall. Trans. B, 18B (1987), 549.

5) Y. Shiraishi, M. Yamashita, Y. Tokunaga and A. Tanaka: Proc. 8th Inter. Conf. on Molten Slags, Flux. Salts, ISS, Warrendale, PA, (2009), CD-ROM.

6) V. V. Baidov and L. L. Kunin: Sov. Phys. Dokl., (English Translation) 13 (1968), 64.

7) H. Bloom and J. O’M. Bockris: J. Phys. Chem., 61 (1957), 515.

8) M. L. Rivers and I. S. E. Carmichael: J. Geophys. Res., 92 (1987), 9247.

9) J. O'M. Bockris and E. Kojonen: J. Am. Chem. Soc., 82 (1960), 4493.

10) Y. Matsuzono, T. Watanabe, M. Hayashi and K. Nagata: CAMP-ISIJ, 20 (2007), 126.

11) Y. Matsuzono, T. Watanabe, M. Hayashi and K. Nagata: CAMP-ISIJ, 22 (2009), 867.

12) R. W. Higgs and T. A. Litovitz: J. Acoust. Soc. Am., 32 (1960), 1108.

13) H. Zhu, T. Saito, Y. Sato, T. Yamamura, K. Shimakage and T. Ejima: J. Jpn. Inst. Met., (Japanese) 55 (1991), 937.

14) T. Ejima and T. Mitsuhashi: J. Jpn. Inst. Met., (Japanese) 39 (1975), 687.

15) T. Ejima and T. Yamamura: Int. J. Thermophysics, 5 (1984), 131.

16) M. Hayashi, H. Yamada, N. Nabeshima and K. Nagata: Int. J. Thermophys., 28 (2007), 83.

17) T. Iida and R. I. L. Guthrie: The Physical Properties of Liquid Metals, 
Oxford University Press, New York, (1988) 91.

18) P. Macedo and T. A. Litovitz: Phys. Chem. Glasses, 6 (1965), 69.

19) K. Takimoto and H. Endo: Phys. Chem. Liq., 12 (1982), 141

20) T. Matsushita, M. Hayashi, and S. Seetharaman: Int. J. Mater. Prod. Technol., 22 (2005), 351.

21) J. David and N. Cheeke: Fundamentals and Applications of Ultrasonic Waves, CRC Press, New York, (2002) 84.

22) O. V. Mazurin, M. V. Streltsina and T. P. Shvaiko-Shvaikovskaya: Handbook of Glass Data, part A, Silica Glass and Binary Silicate Glasses, Elsevier, Amsterdam, (1983) 213.

23) J. Krautkmmer and K. Kmutkramer: Ultrasonic Testing of Materials, 4th ed. Springer Verlag, New York, (1990) 562.

24) Rika Nenpyo (Chronological Scientific Tables), ed. by National Astronomical Observatory, Maruzen Co., Ltd., Tokyo, (2001) 438.

25) R. Turner, E. D. Crozier and J. F. Cochran: Canadian J. Phys., 50 (1972), 2735

26) S. Ernest, J. Glinski and B. Jezowska-Trzebiatowska: Acta Phys. Pol.
Ser. A, 55 (1979), 501.

27) N. L. Laberge, V. V. Vasilescu, C. J. Montrose and P. B. Macedo: $J$. Am. Ceram. Soc., 56 (1973), 506.

28) J. A. Bucaro and H. D. Dardy: J. Appl. Phys., 45 (1974), 5324

29) L. Shartsis, S. Spinner and W. Capps: J. Am. Ceram. Soc., 35 (1952), No.6, 155.

30) L. Šašek and A. Lisý: Sb. Vys. Sk. Chem. Technol. Praze, Chem. Technol. Silik., L2 (1972), 165.

31) L. Šašek and A. Lisý: Sb. Vys. Sk. Chem. Technol. Praze, Chem. Technol. Silik., L2 (1972), 217.

32) G. Heidtkamp and K. Endell: Glastech. Ber., 14 (1936), No.3, 89.

33) L. Šašek and S. Kasa, Silikáty: 14 (1970), No.1, 75.

34) J. F. Stebbins, I. S. E. Carmichael and L. K. Moret: Contrib. Mineral. Petrol., 86 (1984) 131

35) I. Prigogine and R. Defay: Chemical Thermodynamics, Longmans, London, (1954) 543 